\title{
SOIL, SITE AND LAND CLASSIFICATION ${ }^{1}$
}

\section{BY J. STAN ROWE ${ }^{2}$}

John Stanley Rowe was born in Alberta and attended University there, specializing in the biological sciences. Later he continued studies in botany and forest ecology at the Universities of Nebraska and Manitoba, taking the Master's and Doctorate degrees. In 1948 he joined the Winnipeg staff of the Federal Forestry Branch, where his studies concerned problems in the fields of spruce regeneration, tree site requirements, and forest classification. He moved to Ottawa in 1957 and at present heads the Ecology Section, Forest Research Branch, Department of Forestry.

\section{$A B S T R A C T$}

Forest management is a kind of land management, and the forester's attention is increasingly drawn to the physical land base from which forestry values derive.

Various approaches to the inventory of forest land are discussed: through soil classification with its inherited agronomic background, through site classification whose yardstick is productivity, through classification using few or many environmental factors, and through classification based on morphological features of the land itself.

Purpose is implicit in all classifications and different purposes lead to different classifications. It is suggested that forestry purposes are best served by a land classification which initially breaks the landscape pattern into geomorphological parts, each relatively constant as to surface materials. These can be further divided into relatively homogeneous forest-land patches or ecosystem units, the basis for study and prediction of productivity. As a means of reducing complexity, land inventory needs to be placed within a geographic framework of regions or zones.

\section{INTRODUCTION}

In Canada with its extensive natural forests, the forester has been primarily a harvester of trees. But now with the steady depletion of accessible forests a re-appraisal of this traditional role is forced, as increasingly it becomes clear that the practice of forestry implies land management. Land is the fundamental resource; it produces most of the renewable resources, the agricultural and forest crops. In the analogy of the fable, the land is the goose and the forest the golden egg; the forester needs to study, understand and carefully husband his "goose" lest the egg-laying cease.

Serving also to draw attention to the land base, and to its potentialities for multiple use, is the contemporary national concern with problems of recreation, streamflow and wildlife. How shall these and other conflicting uses be reconciled with forestry? The question casts the concept of forest wealth in a new light: in terms of productivity measured not only as wood but as all the values that geographic location, physiography, climate and vegetation confer on the land.

\footnotetext{
${ }^{1}$ Based on a paper read at the 7 th meeting of the B.C. Soils Advisory Committee, January 31 and February 1, 1962.

${ }^{2}$ Research Officer, Forest Research Branch, Department of Forestry, Ottawa.
} 
Every valuable resource should be inventoried and, for example, the same kind of effort directed to forest inventory ought also to be directed to taking stock of the forest land. For it is important that, in addition to knowing what wood supplies are on hand, the forest manager also know what types of land he has, with their geographic locations and sizes, so that his accumulating knowledge and experience in all facets of management can be tied to this physical base. He needs to know the characteristics of different terrain types, for these not only determine potential for productivity but also influence choice of appropriate techniques for silvicultural practice, forest protection and timber extraction.

Specifically, some of the uses of a land inventory are these: For provincial inventories and company operations it may be desirable to know the acreages of different land types by site classes, and from these the predicted yields and values of products under proposed levels of management. Compartments and working circles can then be laid out as areas of equal productivity rather than as equal areas of unknown productivity. Knowledge of the terrain allows definition of areas suitable for logging in particular seasons, providing also information of use for road location and construction. The physiographic base is useful in the planning of forest protection, for it is clearly related to the fire- and disease-susceptibility of the stands it bears. Relationships with silvicultural practice are well known: site classification, as land classification, is essential for the selection of the best suited tree species for any given area, for soil preparation in the interests of natural and artificial regeneration, for calculating spacing of seedlings and anticipating competition, for improvement of forest growth by fertilization and drainage, for the rational development of tree-improvement, and for varietal-testing research.

What is the most useful way to take inventory of forest land; what particular features are of fundamental importance for classification and mapping? The literature dealing with classification of soils, forest sites and land indicates rather wide differences of opinion. Perhaps a critical look at the bases of soil, site and land studies can help to resolve such differences as spring from unexamined assumptions and specialized purposes within these related geographic fields.

An introduction to the subject of forest soils and forest sites is provided by an examination of the ideas and methods of some of those engaged in such studies in the United States. There are several advantages in looking at what is going on in our neighbour country: more workers are involved, there is a larger body of relevant literature and a correspondingly greater attention to theoretical considerations. Also, holding the problems at arm's length, so to speak, may perhaps be conducive to a more disinterested appraisal of them here in Canada.

\section{THE SOIL INDIVIDUAL}

First, a brief look at the Soil Survey, U.S. Department of Agriculture. It began some sixty years ago with a utilitarian motivation, viz. to classify soils for agricultural use, and this built-in agronomic bias has had a continuing influence on its development. In the words of Riecken and Smith (1949); "Through the years, the (soil) series has come to mean a landscape unit that has a narrow range of soil properties, most of which are significant 
to agriculture", and in a similar vein Gardner and Retzer (1949) pointed out that "The lower categories of soil classification, particularly the soil phase, . . . have been directed more toward interpretation for production and management of farm crops than for production and management of forest crops".

There has been strong criticism of the utilitarian orientation of soil science (Nikiforoff 1959), and efforts to expurgate this particular taint are apparent in other recent writings (Whiteside 1959, Anon. 1960). Attempts to establish "soel" or soil individuals, free of human purpose except that of giving pedology a "pure science" certificate, are perhaps misguided and unnecessary. It seems that success along these lines can only be achieved by ignoring the problem of boundaries.

The soil mantle of the earth forms a gradational continuum; it is not a mosaic of discrete, self-defined patches. Soil individuals are therefore creations of man, their boundaries set according to what he sees of interest in the landscape. Quoting Riecken and Smith (1949) again: "The range in properties of the soil unit or individual to be created or defined will depend on two factors, namely, the pedogenic concepts, and the practical uses of the soils", and one might add that the first is influenced and moulded by the second from the beginning. It is man's sense of importance, based on his interests that sets limits to the variability allowed within one "individual" and selects differentiating properties by means of which the defining lines are drawn. Acceptance of the fact that soil individuals are purposive creations rather than "given" natural bodies need not debase pedology; on the contrary, it would seem to confer on it the freedom and flexibility necessary for attack on the manifold problems associated with the skin of the earth.

\section{TAXonomy and Two-DImensional Morphology}

Changing concepts of soil classification seem to be leading soil science back to its geographic source in land classification. Marbut's emphasis on the taxonomic primacy of the soil profile created a gap between soil classification and mapping which has not yet been fully bridged although the outlook is increasingly hopeful. Whiteside (1954) has outlined the changes in criteria used in soil classification since Marbut, one of which is increased attention to the fact that soil morphology is not just two-dimensional (a profile) but three-dimensional, including surface form. The idea that soils are "little landscapes" (Ableiter 1949) and that geomorphological units correspond to soil units (Wooldridge 1949) is not new although its implications remain to be fully explored; the historical pre-occupation with soil morphology as revealed only in the vertical slice dies hard (Jones 1959).

Why has the two-dimensional vertical profile assumed an almost exclusive importance in pedology? One probable reason relates to ease of observation: though the surface shape is readily apparent, the internal, horizontally-extended structure is not. A more important explanation perhaps relates to the relatively constant form in the horizontal plane of agricultural lands which, by and large, occupy level to gently rolling terrain. So long as surface shape and horizontal structure are relatively uniform, significant variations in the soil body will be faithfully reflected by variations in profile morphology. It is when geomorphology is variable, as on rough forest land, that the twodimensional vertical profile loses much of its significance. It then becomes 
necessary to recast the definition of the soil. unit as a three-dimensional segment of the landscape, for the "soil series" unit in its usual interpretation has limited applicability to broken or steeply sloping land.

\section{The "Natural" SoIl Class}

One aspect of soil taxonomy, and indeed of taxonomy in general, around which there seems to be some confusion needs to be examined, viz. the question of what are variously called "natural", "basic" or "scientific" classifications. Any classification is an intellectual exercise whereby given series of data are clipped together in one of a number of different ways depending on the purpose of the classifier. Broadly speaking, the purpose of all classifications is to enable the classifier to make inductive generalizations about the data of interest. In the biological sciences a "natural group" classes together individuals which have a large number of attributes in common, whereas in artificial groups the individuals concerned possess a smaller number of common attributes (Gilmour 1940). Thus a natural class can be used for a wider range of inductive generalizations than can an artificial class, but the difference between the two is one of degree and not of kind. Furthermore, a natural classification-the grouping that seeks to utilize as many as possible of the attributes of the individuals under consideration-may be less useful in spheres of particular scientific interest than a number of artificial classifications tailored to need.

In the literature on soils a somewhat different interpretation is attached to "natural classification". The 7th Approximation of the U.S. Soil Classification (Anon. 1960), which presumably epitomizes current thought on the subject, gives "natural classification" the meaning of a taxonomy based on the hierarchical organization of selected morphological features, especially the stable quantitative ones. No one would question the importance of morphology to natural classification, for similarities in form and structure usually establish similarities in function also. However, the accent on stability, though intellectually satisfying, may favour selection of narrowly-important characteristics over broadly-important ones. Also there is no logical reason why supplementary attributes-physiological, ecological and distributionalshould not also be used. More serious however is the implication which runs like a thread through a good deal of the literature on soil classification that the "natural" classification, on which "technical" or "interpretive" classifications for land use are built, is not itself interpretive. Clearly a natural classification of soils is defined by choice of criteria, guided by a sense of importance. The basic classes (series, type and phase) have no necessarily fixed amplitude except that established by tradition; they can be expanded or contracted to suit particular needs. It is well known, for example, that soil series comprising soils suitable for intensive use are defined more narrowly than those comprising soils suitable only for extensive use (Kellogg 1958).

\section{FOREST SITE}

Turning next to an examination of "site" we find this a vaguer subject than "soil". The reason is that "site" refers to no objective thing; like its synonym "environment" (and like the concept "soil fertility") it derives its meaning and importance at second hand from another center of interest, the forest. 
Since in it usual meaning "site" is that indefinite milieu that determines forest production, the direct way to describe it is obviously to take the measure of the growth of the trees themselves. Estimates of productivity are essential for the practical valuation of forest areas, and opinions on this subjeot differ mainly as to the relative merits of various growth-rate indices and the means of deriving them. Thus, for example, Vincent (1961) recently reexamined the reliability of height-age, pointing out pitfalls and stressing the need for caution in assessing potential productivity by means of "site index"; Smith et al (1960) argued that height-age is the best index available and indicated how some of its limitations can be overcome; Holmes and Tackle (1962) proposed basal area as a better measure of site quality, because of the influence that density exerts on height growth in lodgepole pine stands.

The numerous difficulties in obtaining trustworthy and unambiguous growth data for site evaluation have turned many workers' attention to the supplemental study of other indicators of productivity, such as minor vegetation, soil profile features and measurable environmental factors. It should be stressed that none of these are alternatives to site indices based on growth, for to be of use each one must be related back to the actual and potential growth of forests.

Plant indicators have proved useful, particularly in the structurally-simple coniferous forests of glaciated terrain, for example in Canada, northern Russia and Scandinavia. In northern coniferous forests an expert field ecologist after careful study of an area can generally produce a reasonably good site classification, based on a three-way correlation between key indicator plants, topographic moisture-nutrient gradients, and forest growth (see, for example, the work in British Columbia of R. H. Spilsbury and his associates, and of Dr. V. J. Krajina and his students). The pitfalls are now well known: chance hazards of the past may have impressed on the vegetation certain patterns that bear no close relationship to contemporary environment, and the vegetation may be "out of step" due to a lag in adjusting to environmental change; the minor species may not reflect soil conditions of importance to the deeper rooted trees, or they may reflect features of no importance to the tree (for example, the feather mosses under conifers are frequently a better measure of canopy density than of site factors important to the trees themselves). Also, after certain kinds of severe disturbance the minor vegetation may be largely destroyed. Perhaps the chief weakness of the plant indicator method is its essential artistry, making its reliability proportionate to the good judgement, training and experience of the user.

Coile (1938) critically examined the classification of site by groundvegetation and concluded that although it had promising features it required the use of considerable "applied imagination". He was particularly aware of the danger of confounding the effects of stand composition and density on minor vegetation., with the effects of site on it. As a safer approach he recommended that site classification be based on those fundamental and permanent features of soil and topography: that are essentially uninfluenced by forest cover, such as aspect, relative topographic position and slope, texture and thickness of the $A$ and B soil horizons, depth to and nature of the soil's parent material. Following his own prescription he proceeded to develop a factorial approach 
at Duke University, expressing in formulae the significant correlations between site factors and forest height-age relationships (site index). Today Coile's methods, reinforced by multiple regression analysis, dominate the field of forest site studies in America.

Pedologists tend to view factorial site classification as naive and superficial. Kellogg (1958) has pointed out that the method is narrowly oriented to management of species rather than to management of soil; it provides no basis for ameliorative practices nor for multiple use of land. Along similar lines Retzer (1958) criticized the lack of attention to taxonomic soils in site growth studies, remarking on the necessity of reappraisal of the same area for every different use if studies are directed to establishing correlations between forest growth and individual site characteristics. The force of these arguments is diminished where the policy of land management is set in a simple pattern, such as conifer monoculture on the coastal plain of the southeastern States. It perhaps needs repeating too that the site classifier has a different field of interest from the pedologist, viz. management of tree crops rather than soils. Interests coincide only insofar as soil adequately represents forest environment. Logically then, the next question is: how well do soils represent forest environment and serve as a basis for forest growth correlations and predictions?

\section{SOILS AS ForEst SITES}

Obviously a soil is only half of the environment of the forest stand on it; the other half is the superimposed air-layer containing the leafy tree parts. Although soil constitutes only one part of "site" it has frequently been considered an excellent indicator of the whole.

Many studies have been made to test the correlation between kind of soil anf dorest growth-rate, some with good results, and some with poor. Retzer (1958) attributed the disappointing results to a general lack of knowledge of soil classification among the foresters carrying on site studies. He recommended that: "Only a highly qualified soils taxonomist who is well acquainted with the soils of his region should be used in site studies, and he should participate in all such studies with the trained forester".

Retzer's conditions of qualified personnel were fulfilled in a study by Farrington and Howard (1958), activated by the need to find how useful the mapping units of the Vermont Soil Survey are in defining forest site differences. They found a generally useful correlation between the soil series and several measures of forest growth, but stated that variations in productivity within some soil units "may be too wide to be acceptable". They also noted that some of the less readily observed characteristics of the soil profile such as texture of the deeper horizons, and such "outside" features as aspect, slope-gradient and position on slope, probably account for differences in productivity.

One may deduce from this that the soil survey unit can perhaps be tailored to forestry use by selection of more significant criteria both in the profile and in the surface morphology. In Carmean's (1961) words "if soil taxonomic units are to be used (to classify oak site quality accurately), either these units must be refined or they must be subdivided into phases based 
on the specific soil and topographic factors that are closely related to forest site quality". However, Coile (1960) expressed pessimism about the practical value of the U.S. Soil Survey classifications and maps, on the grounds that they are deliberately non-utilitarian "science and art for the sake of science and art". He found it necessary to map soils for timber-growing in his own way, using profile features of proven importance such as deep soil layers which the standard 42-inch Soil Survey auger cannot reach. Stoeckeler (1961) was of the opinion that the deficiencies of soil survey maps for forestry use could be traced to the less accurate mapping of forest land than of agricultural land. According to him the U.S. Forest Service is attempting to remedy the situation; it is currently mapping 21 pilot areas in the national forests "to produce maps of real value to the forest land manager in all of his activities concerned with soil". In this the Forest Service is co-operating with the National Co-operative Soil Survey including the Soil Conservation Service and soil classification specialists in the various State universities and agricultural experiment stations, to develop standards and quality equivalent to that of the nationwide soil survey in the Department of Agriculture.

In summary, it seems that soils are useful though necessarily incomplete measures of forest production potentialities. Their value for forestry use can be increased by re-casting the concept of the soil unit from that derived by continuous contact with agronomy to one with significance for forestry. Criteria of significance can be established by common sense, ecological studies and factorial soil-growth analyses. As Ahn (1960) stated, a soil classification is likely to be satisfactory to the forester only if it is made with his specific needs in mind and only insofar as the importance of soil characteristics to forestry are known. Admittedly, other soil classifications will be of value to the forester to the extent that the criteria used at different levels and their possible relevance to tree growth are understood.

\section{A Geographic Framework for Correlating Yield and SoIl-Site}

No matter how well soils are defined, mapped and studied, they cannot be expected to provide complete answers to problems of land management for forests or agricultural crops. Too many important environmental influences exist apart from soils: what Farrington and Howard (1958) called the "outside the profile" biotic, climatic and physiographic factors, and what Clark (1938) and Moss (1954) called the soil's "site". Only when these extraneous influences are relatively constant will a good correlation between soils and plant growth show up.

The uniformity of the extra-soil conditions in the southeastern States where Coile has worked (in plantations of pines on the sandy coastal plain) have undoubtedly contributed to his success. Hodgkins (1960) examined the methods of published soil-site index regression studies and concluded that for best results such studies ought to be confined to small, relatively uniform areas. More recently Della-Bianca and Olson (1961) re-examined the 65 odd articles published to date on soil-site and tree relationships. Emphasizing the local significance of the correlations discovered, they pointed out that relationships found in one area for one species do not necessarily hold in other areas for the same or different species. In their own study-an attempt to relate growth 
of Piedmont hardwood and pine-hardwood forests to 63 different soil and site factors - they failed to find more than a partial solution to the problem of predicting tree growth. They suggested that studies of this nature ought to be even more restrictive than heretofore as to size of area and kind of conditions encompassed. In other words, a geographic stratification of land is needed to provide a framework within which reliable soil-site and growth relationships can be established. The old "zonality" concept in soil classification, regardless of its theoretical shortcomings, was a step in the right direction so far as soil use is concerned.

The geographic regionalization of land that will guarantee close soil-site and forest correlations is one providing divisions that are relatively homogeneous in relief, in geological substratum and in pattern of topography. Given uniformity of relief and geology, local climate and native vegetation will closely follow in pattern the pattern of topography. Under such conditions the growth of trees is likely to be correlated closely with soil-sites, particularly if the latter are "objectified" as units of topography-soil, i.e. as catena members in the sense of Bushnell (1944) or soil "associates" as used by Ellis (1932).

\section{Classifying Land as Total Environment or "Total Site"}

An alternative to classification of soils or of soil factors, either of which yields units or factor complexes from only the basal environment of plants, is the classification of land in its wide sense, using selected significant attributes. For example, the California Soil-Vegetation Survey has integrated classification of the plant cover with its classification of soils (Zinke 1960), while in Australia a system using geology, climate, topography and vegetation, in addition to soils, has been developed (see for example Christian 1952, Coaldrake 1961).

Hills' aim, as set forth in numerous publications (Hills 1952, 1958; Hills and Pierpoint 1960) based on work in Ontario, is a hierarchical classification of land units (site regions, landscapes, land types, sites) synthesized from gradient classes of climate, relief, geology, soil and vegetation, in the light of observed interactions of these land features. When characterized by their stable structural parts, the basic site units are called "physiographic sites." They are segments of particular landforms, differentiated primarily by soil moisture regime, depth of soil mantle, and local climate as inferred from topographic position and vegetation. The similarity to "soil associates" and "catena members" will be noted.

The land types (patterns of sites) are classes of relatively uniform geological materials. Because they are defined within a regional framework, they are also assumed to develop similar late-successional or "climax" patterns of vegetation and soils. The large geographic units-the site regions-are defined with the conviction that each has within its boundaries a relatively uniform climate, as indicated by a uniform "fit" of vegetation to landform throughout. This mutual dependence in definition of the three levels of classification confers an inner consistency: the region being defined by the ecological relationships of vegetation and landform, and each site and land type deriving its climatic consistency by virtue of inclusion in a certain region.

The close integration and mutual dependence of all elements at all levels in the classification makes Hills' scheme difficult to comprehend and to 
apply by any excepting those who have worked in close association with him. Nevertheless one important aspect is clear: the taxonomic unit is the physiographic site (segment of land type) rather than the soil. As soil profiles are, like the vegetation, an expression of total site, they are set within and subordinate to the framework of physiographic site. This reverses the usual Soil Survey procedure which makes the soil profile type of key significance. To Hills, the soil profile type is not the key taxonomic entity; he treats it as but one of the characters of mappable site, having importance as an indicator of past history and present productivity. It follows that different sites may have apparently similar soil profiles, and different profile types may occur within the same site type.

The chief importance of Hills' approach lies in his stress on landform and surface geology as the integrating framework for vegetation, soils, local climate and "site". His technique of ranking environmental factors on gradient scales provides a useful means of comparing land areas and of building up concepts of the types (Farrar 1960). Furthermore, in every aspect of field survey one finds in his methods an encouragement to search for relationships, to look at land with the ecologist's eye rather than with that of the narrow specialist.

\section{Classification of Land as ObJectified ENVIRonMent}

The Federal Forestry organization has 2 : nng history of attention to "site classification", influenced strongly by the pi. neer work of Heimburger (1934, 1941) using plant indicators and by the later contributions along similar lines of Sisam (1938), Ray (1941) and Linteau (1955). More recently the influence of Hills' (1952) physiographic approach has been felt. A synthesis of previous approaches in a logical way is now suggested through use of the "ecosystem" concept. An ecosystem is here defined as a perceivable unit of the landscape, homogeneous both as to the form and structure of the land and as to the vegetation supported thereon.

First it needs to be reiterated that environment can be considered both as a complex of "factors" and as an objective entity, viz. the more inclusive system surrounding or associated with the object of interest (Rowe 1961). This is exemplified nicely in the dual conception of "soil" which, to the soil scientist, is an objective system worthy of independent study, and to the forester a conglomeration of environmental factors impinging on forest stands. The total objective environment of a forest stand consists of the soil stratum or rooting zone plus the superimposed air-stratum supporting the stems and leafy plant parts. This two-layered "box" in which plants and animals, soils and local climate interact is the objective ecosystem, the substantial environment of the entire tree in the same way that soil is the substantial and immediate environment of the tree root. At the same time but more abstractly it is an interacting complex of (a) biota, climate, physiography, etc. (Hills' "total sito"), (b) "genetic factors" (Jenny 1941, 1961), (c) light, heat, moisture, nutrients (Bakuzis 1959).

Individual forest ecosystems are, like soil individuals, ad hoc units "chosen" out of a landscape continuum by the use of appropriate criteria guided by purpose. Just as with soils, they ought to be identified and classified using important morphological (structural and compositional) features of the whole 
system, e.g. the geomorphology of the substratum, the soil profile, the topoclimate profile, the physiognomy of the total vegetation. Forest ecosystems can be studied as discrete objects both physiologically (in terms of nutrient cycle, internal water movement, heat transfer, etc.) and ecologically (as influenced by neighbouring systems or by external factors of climate, etc.). Just as the physiology of two trees of similar form, structure and composition (members of the same species) is expected to be alike, providing they are set in the same milieu, so ecosystems of similar morphology are expected to function and produce similarly within the same geographic region. The importance of regional identification and study of significant land-forest systems (ecosystems) becomes obvious.

The identification and study of forest ecosystem units, which in a given region appear to be important for forestry purposes, provides a framework for classifying "sites", i.e. classifying the kinds of landform-soil units in terms of their forest potential. At this point an interpretation of the physiographic bases of the ecosystem units must be made, based on prior knowledge of the wholes. The classification will fasten attention on landform and soil, synthesizing a composite picture of the possibilities of any unit area from consideration of the various ecosystems observed, studied and measured on that same geomorphological class of landform-soil.

\section{Procedure for LaNd Classification for Forestry PURPoses}

Lacate (1961) has briefly outlined a procedure for field investigations of forest land resources, based on the preceding rationale. Landscape "systems" of varying inclusiveness from the large and unique down to the small and repetitive are inventoried by inspection of aerial photographs with ground survey control. As he pointed out, the number and size of the land units (vegetation-soil-terrain units) that are recognized in an area are governed by purpose and the nature of the problems to which the classification will be applied. The units will be few in number if only a broad inventory of forest land resources is required but they may be numerous if detailed research investigations are planned in the study area.

A reasonable approach seems to be the initial delineation and classification of those units of land that can be discriminated readily on mile-to-the-inch aerial photographs, i.e. those units set off from one another by observable "breaks" or changes in the pattern of surface materials or bedrock, accompanied by changes in topographic pattern or relief and vegetation. Such "medium-scale" units of the landscape will be in the size-range of the "soil association" of Ellis (1932), the "natural land type" of Veatch (1941), the "catena" of Bushnell (1944), the "land system" of Christian and Stewart (1947) and the "land type" of Hills (1952), providing a frame of reference within which further divisions can be made according to need.

The possibilities for agreement among different workers in soils, forestry, geomorphology and geography are perhaps greatest at the level of the large land units such as those just mentioned, where clear differences in the surface geological materials and in the matching catenas of soil and vegetation can be seen. Although the various specialized parts - the forest ecosystem unit, the soil series, forest site, vegetation community-may not all coincide with one another, they all can be fitted within the framework of that pattern. 
It is often argued that the best multi-purpose classification is a very detailed one, providing small units that can be rearranged and grouped in various ways to provide any required specialist classification. As Gibbons (1961) has pointed out, this is true only if the detailed classification is based on criteria of universal importance, an impossibility of course. Inasmuch as it is easier to pick out significant geographic boundaries at the small than at the large scale it seems preferable in land classification, where the interests of several different disciplines meet, to start from the large mutually acceptable landscape units and "divide down" for specific purposes. For much forestry work the ultimate division-the unit of the land pattern that is homogeneous as to forest, soil and geomorphology-will be what has been called here the "forest ecosystem". Lacate (op. cit.) has suggested that the large land pattern or "land type" can be adequately described for most purposes in terms of its catena of forest ecosystem units, their proportionate occurrence and their spatial relationships.

In the other direction, considering the larger landscape divisions, a geographic framework is necessary in order to set more or less arbitrary limits to the allowable variations in land types and their divisions. As previously mentioned, the most useful regionalization is one that delineates major areas that are relatively homogeneous as to vegetation, relief-topography and geology. If these observable criteria are used, then climate the unseen is automatically taken into account. The "Site Region" criterion - similar vegetation development on similar landforms - with its implication of climatic homogeneity, does not seem defensible in the terms of its definition. The "Site Region" is however defensible as a practical geographic unit-like any other that serves to reduce geographic variation by dividing complex into simpler patterns of land.

\section{Literature Cited}

ANON. 1960. Soil Classification - A comprehensive system. 7th Approximation. Soil Survey Staff, Soil Conserv. Service, U.S.D.A.

ABLEITER, J. K. 1949. Soil classification in the United States. Soil Science 67:183-191.

AHN, PETER. 1960. The mapping, classification and interpretation of Ghana forests soils for forestry purposes. Proc. 5th World Forestry Congress, Seattle, Wash. Aug. 29-Sept. 10, 1960.

BAKUZIS, E. V. 1959. Structural organization of forest ecosystems. Minn. Acaderny of Science 27:97-103.

BUSHNELL, T. M. 1944. The catena-drainage profile key-form as a frame of reference in soil classification. Soil Sci. Soc. Amer. Proc. 9:219-222.

CARMEAN, W. H. 1961. Soil survey refinements needed for accurate classification of black oak site quality in southeastern Ohio. Soil Sci. Soc. Amer. Proc. 25:394-397.

CHRISTIAN, C. S. 1952. Regional land surveys. Jour. Australian Inst. Agric. Sc. $18(3): 140-147$.

CHRISTIAN, C. S., and G. A. STEWART. 1947. North Australian regional survey 1946, Katherine-Darwin Region. Mimeo C.S.I.R.O., Melbourne.

CLARKE, G. R. 1938. The study of the soil in the field. 2nd edition. The Clarendon Press, Oxford.

COALDRAKE, J. E. 1961. Ecosystem of the Coastal Lowlands, southern Queensland. Bull. 283, C.S.I.R.O., Melbourne, Australia.

COILE, T. S. 1938. Forest classification: classification of forest types with special reference to ground vegetation. Jour. For. 36:1062-1066.

COILE, T. S. 1960. Summary of soil-site evaluation. In: Southern Forest Soils, Eighth Annual Symposium 1959. Louisianz State Univ. Press, Baton Rouge, La. pp. 77-85. 
DELLA-BIANCA, L., and D. F. OLSON. 1961. Soil-site studies in Piedmont hardwood and pine-hardwood upland forests. Forest Science $7(4): 320-329$.

ELLIS, J. H. 1932. A field classification of soils for use in the Soil Survey. Scientific Agriculture 12:338-345.

FARRAR, J. L. 1960. The use of factor gradients in evaluating site. Proc. 5th World Forestry Congress. Seattle, Wash.

FARRINGTON, R. A., and M. HOWARD, Jr. 1958. Soil productivity for hardwood forests of Vermont. First North American Forest Soils Conference Proc., East Lansing 1958. Bull. Agr. Expt. Sta., Mich. State Univ. pp. 102-109.

GARDNER, R. A., and J. L. RETZER. 1949. Interpretive soil classification: Timber range and watersheds. Soil Science $67(2): 151-157$.

GILMOUR, J. S. L. 1940. Taxonomy and philosophy. In "The New Systematics". Ed. Julian Huxley, Oxford, Clarendon Press. pp. 461-474.

HEIMBURGER, C. C. 1934. Forest site studies in the Adirondack region. Cornell Unir., Agr. Expt. Sta. Memoir 165.

HEIMBURGER, C, C. 1941. Forest site classification and soil investigation on Lake Edward Experimental Area. Canada, Dept. of Mines and Resources, Forestry Branch, For. Res. Div. Silv. Res. Note No. 66.

HILLS, G.A. 1952. The classification and evaluation of site for forestry. Ont. Dept. of Lands and Forests. Research Report No. 24.

HILLS, G. A. 1958. Soil-forest relationships in the site regions of Ontario. First North American Forest Soils Conference Proc., East Lansing 1958, Bull. Agr. Expt. Sta., Mich. State Univ. pp. 190-212.

HILLS, G. A. and G. PIERPOINT. 1960. Forest site evaluation in Ontario. Ont. Dept. of Lands and Forests. Research Report No. 42.

HODGKINS, E. J. 1960. Forest Site Classification in the Southeast: an evaluation. In: Southern Forest Soils, Eighth Annual Symposium 1959. pp. 34-48.

HOLMES, J. R. B., and D. TACKLE. 1962. Height growth of lodgepole pine in Montana related to soil and stand factors. Bull. 21, Montana Forest and Conserv. Expt. Sta., Missoula, Mont.

JENNY, H. 1941. Factors of soil formation. McGraw-Hill, N.Y.

JENNY, H. 1961. Derivation of state factor equations of soils and ecosystems. Soil Sci. Soc. Amer. Proc. 25:385-388.

JONES, T. A. 1959. "Soil classification - a destructive criticism". Jour. Soil Sci. $10(2): 196-200$

KELLOGG, C. E. 1958. A look at future forest soil problems. First North American Forest Soils Conference Proc., East Lansing, 1958. Bull. Agr. Expt. Sta., Mich. State Univ. pp. 1-5,

LACATE, D. S. 1961. A review of land type classification and mapping. Land Economics $37(3): 271-278$

LINTEAU, A. 1955. Forest site classification of the Northeastern Coniferous Section Boreal Forest Region, Que., Can. Dept. N.A.N.R., For. Br. Bull. No. 118.

MOSS, H. C. 1954. Soil Classification in Saskatchewan, Canada. Jour. Soil Science 5(2):192-204.

NIKIFOROFF, C. C. 1959. Reappraisal of the soil. Science 129(3343):186-196.

R.AY, R. G. 1941. Site types and rate of growth, Lake Edward, Champlain County, P.Q. Canada, Dept. Mines and Res. For. Br. For. Res. Div. Silv. Res. Note No. 65.

RETZER, J. L. 1958. Soil-a factor affecting the distribution and growth of native and exotic forest regetation. First North American Forest Soils Conference Proc., East Lansing 1958. Bull. Agr. Expt. Sta., Mich. State Univ. pp. 110-115.

RIECKEN, F. F., and GUY D. SMITH. 1949. Lower categories of soil classification: Family, Series, Type, Phase. Soil Science 67 (2):107-115.

ROWE, J. S. 1961. The level-of-integration concept and ecology. Ecology 42(2):420-427.

SISAM, J. W. B. 1938. Site as a factor in silviculture. Can. Dept. Mines and Resources, For. Res. Div., Silv, Res. Note No. 54.

SMITH, J. H. G., J. W. KER, and L. HEGER. 1960. Natural and conventional height-age curves for Douglas fir and some limits to their refinements. Proc. Fifth World Forestry Congress, Seattle, Wash. Aug. 29 - Sept. 10, 1960.

STOECKELER, J. H. 1961. Soil and water management for increased forest and range production. Soil Sci. Soc. Proc, 25(6):446-451. 
VEATCH, J. O. 1941. Agricultural land classification and land types of Michigan. Mich. Agr. Expt. Sta. Bull. No. 231.

VINCENT, A. B. 1961. Is height/age a reliable index of site? Forestry Chronicle 37 (2):144-150. WHITESIDE, E. P. 1954. Changes in the criteria used in soil classification since Marbut. Soil Sci. Soc. Amer. Proc. $18(2): 193-195$.

WHITESIDE, E. P. 1959. A proposed system of genetic soil-horizon designations. Soils and Fertilizers 22(1):1-8.

WOOLDRIDGE, S. W. 1949. Geomorphology and Soil Science. Jour. Soil Sci. 1:31-34.

ZINKE, P. J. 1960. The soil-vegetation survey as a means of classifying land for multiple use forestry. Proc. Fifth World Forestry Congress, Seattle, Wash. Aug. 29 - Sept. 10, 1960. 